\title{
Association of C-reactive protein positivity among groups of patients with knee osteoarthritis in Erbil
}

Accepted: 18/9/ 2016

\begin{tabular}{l} 
Helen Ahmed Pirdawood* Niaz J awad ** \\
\hline \multicolumn{1}{c}{ Abstract } \\
Background and objective: Osteoarthritis is the most common joint disease and \\
a leading cause of disability. Increased circulating levels of C-reactive protein have been \\
associated with prevalent knee osteoarthritis. This study aimed to assess the association \\
between C- reactive protein positivity in patients with knee osteoarthritis in Erbil \\
Methods: Data from 100 participants in this case-control study were enrolled from May $1^{\text {st }}$ \\
to December $1^{\text {st }}, 2015$ in Rizgary Teaching Hospital in Erbil city. Data were divided into two \\
groups. The cases included 50 patients ( 17 male and 33 female) with a mean age of 58.9 \\
\pm 3.8 years and diagnosed with primary knee osteoarthritis of one or both knee joints. \\
Controls included 50 persons ( 17 male and 33 female) with a mean age of $58.1 \pm 3.9$ years \\
without knee osteoarthritis and matched for age, sex, and body mass index. C-reactive \\
protein qualitatively measured. Patients were radiologically assessed by Kellgren and \\
Lawrence grading scale (grade $0-4)$. \\
Results: C-reactive protein was positive in 41 out of 50 (82\%) of knee osteoarthritis \\
patients compared to 3 out of $50(6 \%)$ of healthy controls $(P=0.001)$. C- reactive protein \\
positivity among knee osteoarthritis patients were significantly associated with body mass \\
index, positive family history of knee osteoarthritis, duration of diseases, and Kellgren and \\
Lawrence grade $(P<0.05)$. No significant association was found with sex, site of knee joint \\
involvement, and knee pain severity $(P>0.05)$.
\end{tabular}

Conclusion: C-reactive protein positivity was significantly associated with knee osteoarthritis compared to healthy controls. Furthermore, body mass index, positive family history of knee osteoarthritis, early osteoarthritis, and Kellgren and Lawrence grade II, were significantly associated with positive C-reactive protein in knee osteoarthritis.

Keywords: Osteoarthritis; Knee osteoarthritis; C-reactive protein; Kellgren and Lawrence grade.

\section{Introduction}

Osteoarthritis (OA) is the most common form of joint disease in humans. ${ }^{1}$ It is characterized clinically by pain and functional limitations, radiographically by osteophytes and joint space narrowing, and histopathologically by alteration in cartilage and subchondral bone integrity, and synovial inflamation. ${ }^{2}$ Rather than one uniform disease, osteoarthritis may be a primary or secondary form of arthritis in patients with other inflammatory arthritis, such as rheumatoid arthritis. ${ }^{3}$ All joints may be affected, but the knee is the most clinically significant site of primary $O A$ involvement. ${ }^{4}$ The causes of disease onset and individual variation in susceptibility and progression remain elusive. A suite of $\mathrm{OA}$ risk factors has been identified, including genetic variation, age, sex, obesity, reproductive status (e.g., postmenopausal) in females, mechanical stresses, leg muscle strength, and related parameters, and history of previous joint trauma. The earliest symptoms of knee osteoarthritis (KOA), are Stiffness $<30$ minutes, joint pain, and swelling. In contrast to inflammatory arthritis, the pain

* Erbil Directorate of Health, Erbil, I raq.

** Department of I nternal Medicine, College of Medicine, Hawler Medical University, Erbil, I raq. 
of osteoarthritis is often exacerbated by activity or weight bearing and relieved by rest. Early symptoms are usually of an insidious nature and often do not correlate well with radiographic abnormalities. Later, extensive bone changes, muscle weakness, and loss of joint integrity can lead to more-dramatic joint deformity and disability. ${ }^{5}$ The acute phase protein C-reactive protein (CRP) is an important inflammatory regulator and measurement of circulating CRP is widely used as a diagnostic tool in acute inflammatory diseases. However, CRP has shown limited value in monitoring the low, but elevated level of inflammation in OA. ${ }^{6,7}$ CRP is produced in the liver upon acutely elevated levels of circulating pro-inflammatory cytokines, such as interleukin (IL) $6 .{ }^{8}$ When CRP is released from the liver; it binds to its receptors and is speculated to accumulate in the inflamed tissue. Here it is gradually degraded by the increased level of proteolytical enzymes and released as fragments into the circulation. ${ }^{9}$ Although the role of inflammation in osteoarthritis has been unclear for a long time and regard as noninflammatory arthritis, significant progress has been made in more recent years, and studies also show that there are ongoing inflammation and synovitis that result in permanent joint damage. ${ }^{10}$ Given this greater appreciation for synovitis in patients with $O A$, inflammation has now been strongly implicated in the pathogenesis of $\mathrm{OA} .^{11}$ In many research studies have demonstrated that circulating levels of CRP, a marker of low-grade systemic inflammation, are modestly elevated in $\mathrm{KOA}$ and are associated with decreased cartilage volume and disease progression. ${ }^{12,13}$ This study is the first, to our knowledge, to determine the associations between circulating inflammatory markers (CRP) in KOA patients in Erbil city, Kurdistan region, and whole Iraq. This study aimed to determine the association between CRP as inflammatory markers in patients with
KOA in Erbil city.

\section{Methods}

This case-control study was conducted in the Rheumatology and Medical Rehabilitation Center in Rizgary Teaching Hospital in Erbil Governorate in IraqiKurdistan region. The data was collected from May $1^{\text {st }}$ to December $1^{\text {st }}, 2015$. A total of 50 patients with osteoarthritis of one or both knees (KOA), diagnosed according to revised criteria of the American College of Rheumatology (ACR) for classification of idiopathic OA of the knee, ${ }^{14}$ were selected by a convenience method of sampling. They were compared with 50 healthy individuals as a control group and matched for age, sex, and BMl of patient's group. Their ages were 50 years and more. Patients with any of the following were excluded: other etiologies of knee joint disease such as post-traumatic and post septic arthritis, primary nodal OA of hand, secondary $O A$ due to systemic inflammatory disease such as rheumatoid arthritis, infectious diseases, cancer, inflammatory rheumatic diseases such as rheumatoid arthritis, connective tissue diseases, gout, and others, acute coronary heart disease, metabolic disorders (such as diabetes), liver failure, renal failure, pregnancy, patients who were on drugs like oral corticosteroids, intra-articular injection, oral non-steroidal anti-inflammatory drugs (NSAID), obese patients $\left(\mathrm{BMl} \geq 30 \mathrm{~kg} / \mathrm{m}^{2}\right)$. Data were collected and recorded on a specially designed questionnaire after getting verbal consent from all participants and after approval from the ethics committee of the College of Medicine at Hawler Medical University and Erbil Directorate of Health (DoH). Full history was taken from all individuals including: age, sex, site of knee OA (unilateral, bilateral), duration of disease, knee pain (pain was assessed using verbal rating scale VRS to (none, mild, moderate, severe), ${ }^{15}$ knee stiffness $<30$ minutes, and crepitus, family history of knee OA, history of drug intake and 
thorough clinical examination was done for individuals in both groups. BMI was calculated by the equation BMI =weight (kg) /height $\left(\mathrm{m}^{2}\right)$, and the patients were classified afterward according to BMI into normal weight $<25 \mathrm{~kg} / \mathrm{m}^{2}$, overweight $25-<30 \mathrm{~kg} / \mathrm{m}^{2}$, obese $\geq 30 \mathrm{~kg} / \mathrm{m}^{2}$. The duration of KOA was classified ${ }^{16}$ to (very early $<1$ year, early between 1-3 years, late $>3$ years). Patients were currently on paracetamol, topical non-steroidal antiinflammatory drugs (NSAID). Weightbearing antero-posterior and lateral $\mathrm{X}$-rays of both knees were taken for patients and controls. Patients were radiologically graded according to the Kellgren-Lawrence grading scale ( $\mathrm{KL}$ scale) grading range between (grade 0 _ grade 4 ). ${ }^{17} 10 \mathrm{ml}$ of blood were withdrawn from the vein by VACUTAINER and collected in VACUTEST gelatin tube. Within 3 hours, the serum was separated by centrifugation using KUBOTA 5200 at $1000 \mathrm{rpm}$ for 3 minutes. The sera were stored at $(-30)$ degrees centigrade to investigate CRP by CRP latex kit (L21CRP.v2). Statistical analysis was done by entering the data on the computer using Microsoft Excel. The statistical package for the social sciences (version 21) was used for data analysis. The results were analyzed using frequency distribution, students' independent two samples t-test and Chi square test. $A P$ value of $\leq 0.05$ was considered statistically significant.

\section{Results}

There was a non-significant statistical difference between study groups for age, $\mathrm{BMI}$ and sex of participants. The mean \pm SD of age and BMI of cases and control group were very close to each other. The mean \pm SD of age and BMl for cases were (58.9 $\pm 3.8,24.2 \pm 1.8$ respectively) and for controls were $58.1 \pm 3.9$ and $24.1 \pm$ 1.9 , respectively $(P=0.6)$. Most of the participants in both groups were female (66\%), $(P=0.9)$. There was a significant statistical association between study groups and family history. Most cases had a positive family history $(74 \%)$ in contrast to $18 \%$ of the controls $(P=0.001)$ as shown in Table 1. There was a significant statistical association between the study groups and CRP. The majority of KOA patients $(82 \%)$ had positive CRP results in reverse; the majority of controls $(94 \%)$ had negative CRP findings. Those with positive CRP results had greater chance to acquire $\mathrm{KOA}(\mathrm{OR}=71.3)$ in contrast to negative CRP $(P=0.001)$ as shown in Table 2 .

Table 1: Demographic baseline characteristics of study groups.

\begin{tabular}{llccc}
\hline \multirow{2}{*}{ Characteristics } & \multirow{2}{*}{ Categories } & \multicolumn{2}{c}{ Study groups } & \multirow{2}{*}{ Cases } \\
& & $58.9 \pm 3.8$ & $58.1 \pm 3.9$ & 0.6 \\
\hline Age & Mean \pm SD & $24.2 \pm 1.8$ & $24.1 \pm 1.9$ & 0.31 \\
BMI & Mean \pm SD & $17(34 \%)$ & $17(34 \%)$ & \\
Sex & Male & $33(66 \%)$ & $33(66 \%)$ & 0.9 \\
& Female & $37(74 \%)$ & $9(18 \%)$ & \\
Family history & Positive & $13(26 \%)$ & $41(82 \%)$ & 0.001 \\
& Negative & &
\end{tabular}

Table 2: Association between study groups and CRP positivity.

\begin{tabular}{lcccc}
\hline CRP & $\begin{array}{c}\text { Cases } \\
(\mathbf{n}=50)\end{array}$ & $\begin{array}{c}\text { Control } \\
(\mathbf{n}=50)\end{array}$ & OR & P value \\
\hline Positive n (\%) & $41(82 \%)$ & $3(6 \%)$ & 71.3 & 0.001 \\
Negative n (\%) & $9(18)$ & $47(94 \%)$ & & \\
\hline
\end{tabular}


There was a non-significant statistical relationship between $\mathrm{C}$-reactive protein and both of gender and site of KOA. Most of CRP negative and positive cases were female and had bilateral KOA $(P>0.05)$. There was a significant statistical relationship between $\mathrm{CRP}$ and $\mathrm{BMI}$ and family history. The majority of the overweight patients and those with positive family history showed positive CRP results
( $P=0.02$, and 0.001 , respectively). Among all factors, positive family history and overweight were associated with the highest risk of developing KOA with positive CRP, their odds ratio (OR) were 57.6 and 5.45 consequently. Negative family history and normal BMI associated with decreased risks and they were protective as shown in Table 3.

Table 3: Association between CRP and baseline characteristics of KOA.

\begin{tabular}{|c|c|c|c|c|c|c|}
\hline Characteristic & Category & $\begin{array}{l}\text { Total } \\
n=50\end{array}$ & $\begin{array}{c}\text { Positive CRP } \\
n=41\end{array}$ & $\begin{array}{c}\text { Negative CRP } \\
n=9\end{array}$ & O.R & $P$ value \\
\hline \multirow[t]{2}{*}{ Sex } & Male & 17 & $15(88 \%)$ & $2(12 \%)$ & & \\
\hline & Female & 33 & $26(78 \%)$ & $7(22 \%)$ & 2.01 & 0.41 \\
\hline \multirow[t]{2}{*}{ BMI } & Overweight & 33 & $30(90 \%)$ & $3(10 \%)$ & & \\
\hline & Normal & 17 & $11(64 \%)$ & $6(36 \%)$ & 5.45 & 0.02 \\
\hline \multirow[t]{2}{*}{ Family history } & Positive & 37 & $36(97 \%)$ & $1(3 \%)$ & & \\
\hline & Negative & 13 & $5(38 \%)$ & $8(62 \%)$ & 57.6 & 0.001 \\
\hline \multirow[t]{3}{*}{ Site of KOA } & Unilateral & 15 & $14(93 \%)$ & $1(7 \%)$ & & \\
\hline & & & & & 4.14 & 0.17 \\
\hline & Bilateral & 35 & $27(77 \%)$ & $8(23 \%)$ & & \\
\hline
\end{tabular}


There was a non-significant statistical relationship between CRP positivity and degree of knee pain and drug intake by patients. In KOA patients with positive CRP had $(81 \%)$ moderate knee pain, (91\%) mild pain and $(60 \%)$ severe knee pain $(P=0.31)$. On the other hand, $91 \%$ of CRP positive patients were on paracetamol, whereas $(100 \%)$ on topical NSAID and $(75 \%)$ combinations of topical NSAID and paracetamol $(P=0.25)$. There was a significant statistical association between duration of KOA with positive $\mathrm{CRP}$ and radiological $\mathrm{KL}$ grades, in which $(93 \%)$ of CRP positive patients had the disease durations between 1-3 years (early $O A$ ). Also, $(76 \%)$ of them less than 1 year (very early OA), few of them (33.3\%) with late OA $(P=0.002)$, furthermore regarding $\mathrm{KL}$ grades $(93 \%)$ of positive CRP patients had Grade 2 ,and $(81 \%)$ they were with grade 3 , in contrary $(100 \%)$ negative CRP were with grade 1 and grade $4(P=0.001)$. The details are shown in Table 4.

\section{Discussion}

It is recognized that inflammation is a contributing factor in OA pathology. ${ }^{18}$ Local productions of inflammatory mediators are well known to contribute to cartilage degradation and synovial cell activation in $\mathrm{OA} .{ }^{19}$ That synovial inflammation may be an important etiological factor in $\mathrm{OA}$ was supported by raised serum $C$ reactive

Table 4: Relationship of CRP positivity and associated factors among Knee OA patients.

\begin{tabular}{|c|c|c|c|c|c|}
\hline Variables & Categories & $\begin{array}{l}\text { Total } \\
n=50\end{array}$ & $\begin{array}{c}\text { Positive CRP } \\
n=41\end{array}$ & $\begin{array}{c}\text { Negative CRP } \\
n=9\end{array}$ & $P$ value \\
\hline \multirow[t]{3}{*}{ Duration } & $<1$ year & 13 & $10(76 \%)$ & $3(24 \%)$ & \multirow{3}{*}{0.002} \\
\hline & $1-3$ years & 31 & $29(93 \%)$ & $2(7 \%)$ & \\
\hline & > 3years & 6 & $2(33.3 \%)$ & $4(66.7 \%)$ & \\
\hline \multirow[t]{3}{*}{ Pain } & Mild & 12 & $11(91 \%)$ & $1(9 \%)$ & \multirow{3}{*}{0.31} \\
\hline & Moderate & 33 & $27(81 \%)$ & $6(19 \%)$ & \\
\hline & Severe & 5 & $3(60 \%)$ & $2(40 \%)$ & \\
\hline \multirow[t]{3}{*}{ Drug intake } & Paracetamol & 12 & $11(91 \%)$ & $1(9 \%)$ & \multirow{3}{*}{0.25} \\
\hline & Topical NSAID & 5 & $5(100 \%)$ & $0(0 \%)$ & \\
\hline & $\begin{array}{l}\text { Paracetamol \& } \\
\text { Topical NSAID }\end{array}$ & 33 & $25(75 \%)$ & $8(25 \%)$ & \\
\hline \multirow[t]{4}{*}{$\mathrm{KL}$} & Grade 1 & 1 & $0(0 \%)$ & $1(100 \%)$ & \multirow{4}{*}{0.001} \\
\hline & Grade 2 & 30 & $28(93 \%)$ & $2(7 \%)$ & \\
\hline & Grade 3 & 16 & $13(81 \%)$ & $3(19 \%)$ & \\
\hline & Grade 4 & 3 & $0(0 \%)$ & $3(100 \%)$ & \\
\hline
\end{tabular}


protein levels, which were associated with progression of $\mathrm{OA} .^{16,20}$ In our case-control study results have demonstrated that there is a significant association between study groups and CRP, in which majority of knee OA patients group (82\%) had positive CRP results in reverse; the majority of controls group had negative CRP findings. Those with positive CRP results had greater chance to acquire knee $O A$ in contrast to negative CRP findings which had a protective effect. This is in accordance with the three studies done in USA ${ }^{20-22}$ where they found a correlation between patients with elevated CRP and the presence of inflammatory changes in patients with KOA. They illustrated that the elevated CRP levels seen in these patients might reflect local inflammation within the joint and Interleukin 6(IL-6) is known to be the chief regulator of CRP production and may have a role in the inflammatory $O A$ process. ${ }^{23}$ Strong correlation between CRP levels and synovial fluid IL-6 levels in OA implicates that IL-6 not only act as a regulator of CRP in OA but also as a possible mechanistic link between elevated CRP. ${ }^{23}$ In Sturmer et al. ${ }^{24}$ studies they found modestly elevated in the plasma of patients with OA compared to age-matched controls, while study done by Pearle et al ${ }^{22}$ in 2007 revealed that the mean CRP level in patients with inflammatory infiltrates was significantly higher than those without inflammation $(4.7 \pm 5.0 \mathrm{mg} / \mathrm{L}$ vs. $1.7 \pm 3.6$ $\mathrm{mg} / \mathrm{L}, P=0.003$ ). We did not found any relation between age and positive CRP in our patients that's similar to Pearle et al. ${ }^{22}$ studies, this is against many epidemiological studies. ${ }^{25}$ Several studies have reported relationships between CRP and various features of $\mathrm{KOA}$, in Spector et al. $^{26}$ and Sturmer et al. ${ }^{24}$ studies a population based, cross sectional study observed increased CRP values in women with radiographically defined knee $O A$. In contrast, our results showed no significant relationship between C-reactive protein and sex. However, most of CRP negative and positive cases were female, in agreement with Stannus et al.$^{25}$ studies, and our results were very similar with Virgina et al. $^{27}$ studies in which $63.7 \%$ of KOA patients were female. One reasonable explanation for this difference could be due to potential geographical factors. However, there was no significant association of positive CRP and site of knee joint involvement, in agreement with another study. ${ }^{24}$ In this study, with a tightly controlled patients group for BMI (obese patients were excluded), regression analysis demonstrated a significant relationship between $\mathrm{CRP}$ and BMI. Most of CRP positive knee OA patients were overweight in contrast to CRP negative patients, were the majority of them had normal BMI so overweight were associated with the highest risk of developing Knee $\mathrm{OA}$ with positive C-reactive protein, this finding was in consistence with Engström et al. ${ }^{28}$ and Virginia et al. ${ }^{27}$ In USA a study done in 2007 contrasted our finding's as they observed no association between systemic CRP ( $r=0.09, P=0.56)$ and BMI $(r=0.004, P=0.97)$ in KOA patients. ${ }^{22}$ Another interesting finding in our study was a significant association between CRP and family history. Most of CRP positive knee OA patients had positive family history, this agreed with Vonk et al. ${ }^{29}$ reported that Micro RNAs (mi RNAs) most likely modulate cartilage metabolism through metabolic and inflammatory mechanisms in $\mathrm{OA}^{30}$ However, no significant association found between CRP positivity and degree of knee pain and drug intake by patients. This contrasted other studies (Miller et al., ${ }^{31}$ Marta et al. ${ }^{32}$ ) but agreed with Arendt et al. ${ }^{33}$ Sturmer et al.. ${ }^{22}$ There were highly significant associations detected in this study between duration of Knee OA and positive $\mathrm{CRP}$ and radiological $\mathrm{KL}$ grades (after were taken into account. for age, sex, and BMI. Most of CPR positive patients had the early OA with Grade II; in contrary, most of CRP negative patients had late OA with Grade IV. These results are inconsistent with findings of studies done in Denmark 2014, ${ }^{33}$ Sweden 2003, ${ }^{34}$ 
Ireland $2005^{16}$ and studies in Japan $2015^{35,36}$ revealing that high-sensitivity CRP was associated with the $\mathrm{K} / \mathrm{L}$ grade and early OA, furthermore increased serum CRP in early phases of OA suggests the presence of low-grade inflammation, which supports a pathophysiological role of inflammation at early stages of the disease process. But this was not observed by Sturmer et al. ${ }^{24}$ and Sowers et al. ${ }^{20}$ in which CRP was mostly related with late KOA and grade IV. Our study has several potential limitations. First our sample size is relatively small. Secondly, we measured CRP for positivity and negativity by qualitative measurement without measuring the level of CRP in which sometimes there is increasing in low level of CRP which is more significant as a marker for local inflammation. The key strength of the present study lie in the measurements of inflammatory markers (CRP) in KOA patient and comparing it with healthy controls with very closely matched for age, sex and BMI, another strength of this study is the exclusion of the confounding factors correlate with positive CRP in KOA like obesity, advanced age, and cardiovascular comorbidity.

\section{Conclusion}

Positive CRP is associated with knee osteoarthritis patients in Erbil city. In patients with KOA relative factor like BMI, positive family history of knee OA, early duration, and $\mathrm{KL}$ grade II were significantly associated with positive CRP. These data raise the possibility that systemic inflammation may play a role in the pathogenesis of knee OA. Other findings show no association between positive CRP and age, the severity of knee pain in most of the patients. Longitudinal follow-up studies employing quantify measurement for CRP level, synovial fluid analysis for IL6, TNF-alpha, arthroscopy and sensitive imaging modalities will be required to determine if the intensity of synovitis and local inflammation plays a critical part in progressive joint damage and pathogenesis of KOA with their relation with CRP level.

\section{Conflicts of interest}

The authors report no conflicts of interest.

\section{References}

1. Amanda EN, Joanne MJ, Silman AJ, Smolen JS, Weinblatt ME, Weisman $\mathrm{MH}$, et al. Osteoarthritis: epidemiology and classification. In: Hochberg MC, editors. Rheumatology. $5^{\text {th }}$ ed. Philadelphia, USA: Mosby, Elsevier; 2011. P. 1706-17.

2. Lane NE, Schnitzer TJ. Osteoarthritis, In: Lee Goldman, Andrew I. Schafer: Goldman's Cecil Medicine. $24^{\text {th }}$ ed. Philadelphia USA: Elsevier; 2012. P. 1672-6.

3. Brooks P. Inflammation as an important feature of osteoarthritis. Bull World Health Organ 2003; 81: 689- 90.

4. $\mathrm{Xu} \mathrm{L,} \mathrm{Zhu} \mathrm{GB,} \mathrm{Wang} \mathrm{L,} \mathrm{Wang} \mathrm{D,}$ Jiang XR. Synovial fluid omentin-1 levels are inversely correlated with radiographic severity of knee osteoarthritis. J Investig Med 2012; $60: 583-6$.

5. Pelletier JP, Martel-Pelletier J. The Novartis-ILAR Rheumatology Prize 2001 Osteoarthritis: From molecule to man. Arthritis Res 2002; 4: 13-9.

6. Bejon $\mathrm{P}$, Byren I, Atkins $\mathrm{BL}$, Scarborough $\mathrm{M}$, Woodhouse A, Lardy-Smith $P$, et al. Serial measurement of the C-reactive protein is a poor predictor of treatment outcome in prosthetic joint infection. J Antimicrob Chemother 2011; 66(3): 1590.

7. Dolzani P, Assirelli E, Pulsatelli L, Addimanda O, Mancarella L, Peri G, et al. Systemic inflammation and antibodies to citrullinated peptides in hand osteoarthritis. Clin Exp Rheumatol 2011; 29(9): 1006.

8. Rhodes B, Furnrohr BG, Vyse TJ. C-reactive protein in rheumatology: biology and genetics. Nat Rev Rheumatol 2011; 7(9):.282

9. Karsdal MA, Henriksen K, Leeming DJ, Woodworth T, Vassiliadis E, Bay-Jensen AC. Novel combinations of Post-Translational Modification (PTM) neo-epitopes provide tissue-specific biochemical markers e are they the cause or the consequence of the disease? Clin Biochem 2010; 804: 43:793.

10. Ehrlich GE. The rise of osteoarthritis, Bull World Health Organ 2003; 81:630-1.

11. Scanzello C, Goldring S. The role of synovitis in osteoarthritis pathogenesis. Bone 2012; 51: 249-57.

12. Sharif M, Shepstone L, Elson CJ, Dieppe PA, Kirwan JR. Increased serum $C$ reactive protein may reflect events that precede radiographic progression in osteoarthritis of the knee. Ann Rheum Dis 2000; 59(4): 71. 
13. Hanna FS, Bell RJ, Cicuttini FM, Davison SL, Wluka AE, Davis SR. High sensitivity C-reactive protein is associated with lower tibial cartilage volume but not lower patella cartilage volume in healthy women at mid-life. Arthritis Res Ther 2008; 10: R27.

14. Altman R, Asch E, Bloch G. Development of criteria for the classification and reporting of osteoarthritis: classification of osteoarthritis of the knee. Arthritis Rheum1986; 29:1039-49.

15. Turk DC, Melzack R. Handbook of pain assessment. New York: Guliford Press; 2001.

16. Benito MJ, Veale DJ, FitzGeraldO, van den Berg WB, Bresnihan B. Synovial tissue inflammation in early and late osteoarthritis. Ann Rheum Dis 2005; 64: 1263-7.

17. Kellgren HJ, Lawrence SJ. Radiological assessment of osteoarthritis. Ann Rheum Dis $1967.501-494: 16$;

18. Goldring $\mathrm{MB}$, Otero $\mathrm{M}$. Inflammation in osteoarthritis. Curr Opin Rheumatol 2011; 23(8): 471.

19. Pierre, Marie Curie M. Osteoarthritis as an inflammatory disease (osteoarthritis is not osteoarthrosis!). Osteoarthritis Cartilage 2013; 21(1).

20. Sowers $M$, Jannausch $M$, Stein $E$, Jamadar D, Hochberg M, Lachance L. C-reactive protein as a biomarker of emergent osteoarthritis. Osteoarthritis Cartilage 2002; 10 (8):595-601.

21. Smith JW, Martins TB, Gopez E, Johnson T, Hill HR, Rosenberg TD. Significance of C-reactive protein in osteoarthritis and total knee arthroplasty outcomes. Ther Adv Musculoskelet Dis 2012; 4(5): 315-.25

22. Pearle AD, Scanzello CR, George S, Mandl LA, SculcoT $P$,Crow MK, et al. Elevated highsensitivity C-reactive protein levels are associated with local inflammatory findings in patients with osteoarthritis. Osteoarthritis Cartilage 2007; 15: 516- 23.

23. Legendre F, Dudhia J, Pujol JP, Bogdanowicz P. JAK/STAT but not ERK1/ERK2 pathway mediates interleukin (IL)-6/soluble IL-6R down-regulation of Type II collagen, aggrecan core, and link protein transcription in articular chondrocytes, Association with a down- regulation of SOX9 expression. J Biol Chem 2003; 278(5): 2903-12.

24. Sturmer T, Brenner H, Koenig W, Gunther KP. Severity and extent of osteoarthritis and low grade systemic inflammation as assessed by high sensitivity $C$ reactive protein. Ann Rheum Dis 2004; 63: 200-5.

25. Stannus O, Jones G, Cicuttini F, Parameswaran V, Quinn, Burgess, et al. Circulating levels of IL-6 and TNF-a are associated with knee radiographic osteoarthritis and knee cartilage loss in older adults. Osteoarthritis Cartilage 2010; 18: 1441- 7 .
26. Spector TD, Hart DJ, Nandra D, Doyle DV, Mackillop N, Gallimore JR, et al. Low-level increases in serum $\mathrm{C}$-reactive protein are present in early osteoarthritis of the knee and predict progressive disease. Arthritis Rheum 1997; 40:723-7.

27. Virginia B K, Thomas VS, Gheorghe L, Jordan B $\mathrm{R}$, Anca DD, Joanne $M$ J. Interpretation of Serum C-Reactive Protein (CRP) Levels for Cardiovascular Disease Risk is Complicated by Race, Pulmonary Disease, Body Mass Index, Gender, and Osteoarthritis. Osteoarthritis Cartilage 2007; 8: 966- 71.

28. Engström G, Gerhardsson de Verdier M, Rollof , Nilsson P M, Lohmander LS. C-reactive protein, metabolic syndrome and incidence of severe hip and knee osteoarthritis, a population-based cohort study. Osteoarthritis Cartilage 2009; 17: 168- 73.

29. Vonk LA, Kragten AH, Dhert WJ, Saris DB, Creemers LB. Overexpression of hsa-miR148a promotes cartilage production and inhibits cartilage degradation by osteoarthritic chondrocytes. Osteoarthritis Cartilage 2013; 21 (1):145-53.

30. Wang X, Hunter D, Xu J, Ding C. Metabolic triggered inflammation in osteoarthritis. Osteoarthritis Cartilage 2015; 23: 22- 30.

31. Miller GD, Nicklas BJ, Loeser RF. Inflammatory biomarkers and physical function in older, obese adults with knee pain and self-reported osteoarthritis after intensive weight-loss therapy. J Am Geriatr Soc 2008; 56(4): 644- 61.

32. Marta I, Fernando E, Fabio MA, Lucy VB, Tania RT, Janini $C h$, et al. Serum Levels of Pro-inflammatory Cytokines in Painful Knee Osteoarthritis and Sensitization. International Journal of Inflammation 2015; 8.

33. Nielsen LA, Thomas NE, Line LE, Kristian KP, Nielsen TG, Hans $\mathrm{CH}$, et al. Association Between Experimental Pain Biomarkers and Serologic Markers in Patients With Different Degrees of Painful Knee Osteoarthritis. Arthritis Rheumatol 2014; 66: 3317- 26.

34. Saxne $T$, Lindell M, Mansson B, Petersson IF, Heinegard D. Inflammation is a feature of the disease process in early knee joint osteoarthritis. Rheumatology 2003; 42: 903-4.

35. Yun $\mathrm{ZH}$, Juwu $\mathrm{CH}$, Guohui $\mathrm{Y}$. Serum and Synovial Fluid Levels of CCL18 are correlated with Radiographic Grading of Knee Osteoarthritis. Med Sci Monit 2015; 21: 840-4.

36. HanadaM, Takahashi $\mathrm{M}$, Furuhashi $\mathrm{H}$, Koyama H, Matsuyama $\mathrm{Y}$. Elevated erythrocyte sedimentation rate and high-sensitivity C-reactive protein in osteoarthritis of the knee: relationship with clinical findings and radiographic severity. Ann Clin Biochem 2015; 51: 11. 